\title{
El periodismo político de Galdós durante el Sexenio Revolucionario
}

\author{
Galdós' Political Journalism \\ during the Revolutionary Six-year Term
}

JORGE VILCHES GARCíA

Universidad de Complutense

Facultad de Ciencias Políticas y Sociología

Departamento de Historia, Teorías y Geografía Políticas

Campus de Somosaguas

28223 Pozuelo de Alarcón (Madrid) (España)

jorge.vilches@cps.ucm.es

iD

RECIBIDO: FEBRERO DE 2021

ACEPTADO: FEBRERO DE 2021

Resumen: La imagen del Galdós republicano con simpatías socialistas no corresponde con las ideas políticas que defendió en la prensa durante el Sexenio revolucionario. En las crónicas parlamentarias que escribió para Las Cortes se mostró monárquico demócrata, fue liberal conservador en la Revista de España y El Debate, y cínico en La llustración de Madrid. Al tiempo, dependiendo del medio para el que escribiera, era despiadado con republicanos, socialistas, radicales y carlistas. El advenimiento de la República lo consideraba una desgracia para España, al mismo nivel que el triunfo del carlismo. Galdós ocultó en su vejez las cabeceras para las que escribió. Es posible que fuera para no perjudicar su imagen final de republicano coherente.

Palabras clave: Revolución de 1868. Republicanismo. Carlismo. Cortes. Periodismo político.

Abstract: The public image of a republican Galdós with sympathies for socialism does not match with the political ideas he stood for in newspapers during the Six-Year Revolution Period. He was royalist and democrat in his parliamentary chronicles; liberal and conservative in Revista de España and El Debate; and cynical in La l/ustración de Madrid. He was ruthless all at once with republicans, socialists, radicals and carlists, depending on the journal or newsletter he was writing for. He thought that the emergence of the Republic would be a misfortune for Spain, similar to carlism. When he became old, Galdós remained silent on which publications he had written for during his lifetime, possibly in order to protect his final public standing of a coherent republican.

Keywords: Spanish Revolution of I 868. Republicanism. Carlism. Spanish Parliament. Political journalism. 


\section{JORGE VILCHES GARCÍA}

\section{INTRODUCCIÓN}

La sensación que tienen muchos estudiosos de la figura de Galdós es que el escritor ocultó sus inicios periodísticos cuando ya estaba en su etapa republicana y socialista. No es de extrañar, ni algo fuera de lo común. Entre I863 y 1873, diez años, estuvo muy ligado al liberalismo de tintes centrados, ya fuera en La Nación de Pascual Madoz, o en las publicaciones de José Luis Albareda'. Era entonces un escritor monárquico, liberal y persona de orden, antisocialista y antitradicionalista, lo que contrasta con la última etapa de su vida. Esa distancia entre su juventud y su vejez podría tener una explicación: la necesidad de acomodarse a la tendencia de la empresa. Es posible, pero innecesario. Está más en consonancia con la tradición republicana y socialista de presentar una coherencia vital y una fidelidad a la ortodoxia. Tampoco es que el escritor canario tuviera un pensamiento político muy refinado, pero sí se puede entresacar su interpretación de su tiempo presente, no la que tuvo cuarenta años después, como es lo habitual en los estudios de la Quinta Serie de los Episodios Nacionales.

Jover Zamora escribió hace décadas sobre la creación del mito de la Primera República a través de la obra de Galdós ${ }^{2}$. El escritor estuvo influido de forma determinante por su creciente compromiso político que confirió a su visión una sobrecarga utópica como contrapunto a la Restauración. Es indudable que, si Galdós hubiera escrito «La Primera República» y «De Cartago a Sagunto» no en 1911 sino en 1886, cuando fue diputado en el grupo de Sagasta, hubieran sido dos episodios muy distintos. Para 1910, según Jover Zamora, Galdós tuvo una inclinación socialista creciente que influyó en su modo de abordar la Historia: criticar el positivismo, el hecho, los acontecimientos, la realidad, para ensalzar la intención, el idealismo, la utopía. Por otro lado, dice el citado historiador, también influyó que en 1911 tenía 68 años y le fallaba la vista, no podía leer y tenía que dictar.

En consecuencia, este trabajo remite solo a la visión que Galdós tuvo de su tiempo vivido, entre 1868 y 1873 , tal y como lo escribió en la prensa de esos años. Sus trabajos periodísticos reflejan sus ideas y análisis de la situación política y de la España de su tiempo en aquel momento, no décadas después. Esa interpretación galdosiana de su época hecha en tiempo real, no elude que el escritor tratara, quizá, de ajustarse a la línea editorial del editor que le pagaba.

\footnotetext{
' Arencibia, 2020a.

${ }^{2}$ Jover Zamora, 199I, pp. III y ss.
} 


\section{EL PERIODISMO POLÍTICO DE GALDÓS}

\section{LA PRENSA EN LA QUE ESCRIBIÓ}

No se sabe a día de hoy todos los periódicos en los que publicó Galdós durante el Sexenio revolucionario, en gran parte porque el mismo escritor lo ocultó en sus escritos autobiográficos. No solo no firmó algunos de los textos, sino que se refería a su actividad periodística de forma vaga y contradictoria. La primera vez que lo hizo fue en 1894 para hablar de su primera novela, «La Fontana de Oro», y solo respecto a El Debate, y luego en 1912. En sus Memorias de un desmemoriado no hay una referencia clara a su actividad periodística. Leo Hoar hablaba de "amnesia intencionalmente selectiva»" ${ }^{3}$ porque hay párrafos de los artículos que publicó en Las Cortes copiados literalmente en sus «Episodios $\mathrm{Na}$ cionales»; en concreto, en «España sin rey» (1907-1908). Esto significa, escribió Hoar, que Galdós guardó los recortes, los utilizó y luego calló sobre su participación en la prensa ${ }^{4}$.

La Revolución de Septiembre encontró a Galdós en Francia. Entonces era redactor de La Nación, un periódico progresista templado en esa etapa inspirado por Pascual Madoz. En ese diario escribía sobre todo artículos costumbristas y culturales $^{5}$. Tras el éxito revolucionario solo escribió un artículo político, en octubre, $y$ fue a favor de corriente.

En 1869 comenzó a colaborar con Las Cortes, un periódico monárquico democrático, escribiendo las «Crónicas parlamentarias» entre febrero y diciembre de 1869. Así lo aseguró en 1920 Víctor Gabirondo, amigo de Galdós, aunque se equivocó en el título de la serie ${ }^{6}$. No fue «La Tribuna del Congreso», sino "Crónica Parlamentaria» - había Cortes, no Congreso todavía-, que recoge sus impresiones de las sesiones constituyentes y posteriores. Esto también lo asegura Leo J. Hoar, estudioso galdosiano, y William H. Shoemaker, el mayor conocedor de la pluma periodística de Galdós 7 .

Rafael María de Labra lo incluyó en 1870 entre los redactores de El Correo de España, pero solo aparece su firma en el artículo literario «Mi calle» (núm. 6, 28 de noviembre de 1870, pp. 24-26), y en un retrato biográfico de Mesonero Romanos (núm. I5, I3 de abril de I87I, PP. 22-23), que ya había publicado en La Nación. Además, en el número 16, del 28 de abril de I87।, presentó el primer capítulo de «La Fontana de Oro», con el título «La Carrera de San Jerónimo en 182 I». No obstante, la investigadora María del Mar Palomo demuestra que no es

\footnotetext{
${ }^{3}$ Citado por Davies, 2009, n. 4.

${ }^{4}$ Hoar, 1973.

${ }^{5}$ Shoemaker, 1977; Andrades, 2003.

${ }^{6}$ Gabirondo, Víctor, «Galdós, periodista», La Libertad, 5 de enero de 1920, p. I. Este texto suele ser citado por su reproducción en la revista La Lectura; revista de ciencias y de artes, I, 1920, pp. 84-85.

${ }^{7}$ Hoar, 1973.
} 


\section{JORGE VILCHES GARCÍA}

el primer capítulo, sino la refundición de los dos primeros ${ }^{8}$. Al pie del texto en El Correo de España el editor indica que es un texto «debido a la pluma de uno de nuestros más asiduos colaboradores». De ser cierto esto habría más artículos de Galdós sin firmar o con seudónimo en dicha publicación.

Al año siguiente comenzó a trabajar para José Luis Albareda como director de El Debate entre su fundación el 16 de enero de 187I y octubre de 1872. Fue un periódico amadeísta patrocinado por el general Prim, quien no llegó a ver su salida. Víctor Gabirondo contó en 1920 cómo se fundó El Debate:

No se me olvidará —solía decir Galdós- la fundación de aquel periódico del general Prim; fue cosa de sueño. Albareda le habló al general. El general escuchó. Volvió a hablar Albareda... De pronto, Prim, con aquellos movimientos rápidos que tenía, abrió un cajón de la mesa, sacó un fajo de billetes, y entregándoselos a Albareda, le dijo: - Vamos a ver ese periódico. - Y lo vimos — decía D. Benito-, y triunfamos con él. Éramos redactores - añadía el maestro- Núñez de Arce, López Guijarro, Ramón Conesa, Ferreras y yo.

El objetivo de El Debate era defender la monarquía constitucional de Amadeo de Saboya, recién votado por las Cortes. Albareda, vinculado a la Unión Liberal, fue diputado constituyente, se opuso a la candidatura Montpensier frente a la de un Saboya, votó con los 191 y formó parte de la comisión parlamentaria que viajó a Italia a ofrecer la corona a Amadeo`. La empresa política necesitaba un periódico popular. Ese fue el propósito de El Debate, pero la ausencia de Prim disminuyó su importancia por la disolución del Partido Progresista ${ }^{10}$.

La redacción se localizó en el número 15 de la calle Fomento, una calle pequeña que todavía hoy empieza en la cuesta de Santo Domingo y termina a la espalda del Senado. En su primer número dijo que su aspiración era procurar que «la monarquía recientemente fundada adquiera toda la robustez, todo el prestigio, toda la fuerza que son necesarios para que el país desarrolle a su amparo sus vitales fuerzas». La herencia progresista de Prim, como es sabido, la disputaron Sagasta y Ruiz Zorrilla. El Debate defendió la postura del primero, colaborador de la Unión Liberal, y se convirtió en uno de los órganos del partido constitucional de Serrano y Sagasta "'. Esa cercanía a la parte conservadora de la revolución hizo que Juan Bautista Topete, cuando creyó que la monarquía amadeísta peligraba seriamente, ya en 1872 , tomara un papel importante en el periódico'2.

\footnotetext{
${ }^{8}$ Palomo, 1994.

${ }^{9}$ Ferreras, José «Excmo. Sr. D. José Luis Albareda», La llustración de Madrid. Revista de política, ciencias, artes y literatura, año II, 47, I5 de diciembre de 187I, p. 359-362.

${ }^{10}$ Sapag, 2006.

" De hecho, las primeras armas políticas de Galdós fueron con el partido de Sagasta en la Restauración.

${ }^{12}$ Ossorio, 1908, p. 449.
} 


\section{EL PERIODISMO POLÍTICO DE GALDÓS}

Galdós solo firmó dos artículos en El Debate, ambos de literatura, aunque confesó que había escrito muchos de política ${ }^{13}$.

Albareda hizo que Galdós escribiera para la Revista de España. Primero publicó «El artículo de fondo» (núm. 75, tomo XIX, 13 abril I87I, pp. 427-440), dos piezas de «Revista Política Interior» en mayo y junio, que era una crónica quincenal de la vida política, y publicó por entregas su novela «El audaz» ${ }^{14}$. En febrero de 1872, Albareda nombró a Galdós director de la Revista de España, haciéndose cargo de la redacción de la «Revista Política Interior» de forma asidua entre enero y septiembre de $1872^{15}$. La Revista de España apareció el 15 de marzo de 1868, meses antes de la Revolución, y lógicamente proclamaba que era «ajena a la lucha de los partidos militantes, y libre de todo compromiso de bandería». No obstante, tras el triunfo de la Septembrina, la «Revista de Política Interior» tuvo un cariz liberal conservador, que pasó, al igual que El Debate, de ser partidario de la conciliación revolucionaria a apoyar al partido constitucional (o conservador constitucional). Galdós estuvo en su primera etapa, entre I87I hasta 1873, momento en el que Albareda compartió la propiedad de la revista con el canario Fernando León y Castillo.

En ese tiempo, además, publicó por entregas «La novela en el tramvía [sic]» en La llustración de Madrid, una magnífica revista dirigida por Eduardo Ga-sset y Artime, que contó con Gustavo Adolfo Bécquer como director literario, y que se imprimía en los locales de El Imparcial ${ }^{16}$. A la finalización de dicha novela Galdós comenzó las «Crónicas de la quincena», en las que quería ajustarse a temas culturales, como hizo en La Nación, y así evitar solaparse con su trabajo en El Debate o en la Revista de España. Tenía la orden de no hablar de política en sus artículos, aunque considerase que "iAcontece algo en la esfera social o en la literaria que no se relacione con la política?»17. Sin embargo, sus "Crónicas» tienen comentarios interesantes sobre la situación del país.

En enero de 1873 comenzó a colaborar en La Guirnalda. Periódico quincenal dedicado al bello sexo, cuya redacción estaba situada entonces en la calle del Barco, número 2, y propiedad del tinerfeño Miguel Honorio de la Cámara y Cruz. Ahí se desentendió del periodismo político con una sección dedicada a «Biografías de damas célebres españolas», y comenzó la publicación de los Episodios Nacionales a finales de año, cuyo título fue aconsejado por José Luis Albareda. Shoemaker

\footnotetext{
13 García Pinacho, 2001, pp. 162-163.

14 Menéndez-Onrubia, 2015.

15 Dendle, 1970. Los textos políticos de Galdós en dicha revista están recogidos en Pérez Galdos, 1982. La presencia de Galdós en la Revista de España en Ballantyne, 1990.

${ }^{16}$ Rubio Jiménez, 2014; Abella y García Escuder, 2010; Gonzalez Yanci, 2009; Arencibia, 2020 b.

${ }_{17}$ «Crónica de la Quincena», La llustración de Madrid. Revista de política, ciencias, artes y literatura, año III, 55, I5 de abril de 1872, pp. 97-99.
} 


\section{JORGE VILCHES GARCÍA}

dice que escribió algunos textos sin firmar en Las Novedades en 1869 y 1870 , y que «quedan todavía sin identificar» 18 .

En este estudio se recogen sus artículos políticos publicados en Las Cortes (febrero a diciembre de 1869), la Revista de España (mayo de 1870 a agosto de 1872), y La llustración de Madrid (I87I). Además, se cita El Debate porque fue su director entre 1870 y 1873 .

\section{DeMÓCRATA EN LAS CORTES DE LA REVOLUCIÓN}

Galdós vio la Revolución de 1868 con alegría, como buena parte de la sociedad española. Echar a los Borbones y a lo que significaban -el cansancio por un sistema que no funcionaba puesto en manos de una oligarquía-, abrió la puerta a las esperanzas. La revolución lo encontró en Francia. Cambió su viaje a Canarias por uno a Madrid y llegó a tiempo de ver entrar en la ciudad al general Serrano. Por entonces era un joven periodista de un diario progresista, La Nación. No se trataba de una de las publicaciones más populares y radicales del progresismo, como fueron La Iberia o El Imparcial, pero sí era respetado por la altura de sus textos. En sus páginas debutó Galdós con 21 años, el 3 de febrero de 1865. Los artículos que había publicado en La Nación no eran políticos, sino culturales y de costumbres ${ }^{19}$. Ya de vuelta en la capital de España escribió el I 3 de octubre en La Nación un artículo muy duro contra la dinastía destronada y los moderados.

Esta inepta familia que ocupó por espacio de siglo y medio el trono de España. ¡Qué familia, santo Dios! En la fisionomía de todos ellos se observan los más claros caracteres de la degradación. Ni una mirada inteligente, ni un rasgo que exprese la dignidad, la entereza, la energía, el talento. No se ven más que caras arrugadas y ridículas, deformes facciones cubiertas de una piel herpética, sonrisas y saludos afectados que indican la mala educación de los niños y el cinismo de los mayores. La indiferente y glacial figura del despreciable Paco forma armoniosa simetría con la efigie del serenísimo mamarracho don Sebastián, sultán de los tuertos, arqueólogos y pintamonas por añadidura ${ }^{20}$.

Galdós veía en la revolución la oportunidad, ahora que se había ido «todo de un puntapié» -escribió en La Nación-, para un cambio liberal que construyera una clase media, un sistema de partidos que diera estabilidad a un régimen basado en la libertad de comercio, educativa y religiosa ${ }^{21}$.

\footnotetext{
${ }^{18}$ Shoemaker, 1977, p. 24; Utt, 1984.

${ }^{19}$ Shoemaker, 1965.

20 «Recuerdos de una fiesta», La Nación, I3 de septiembre de 1868.

21 Sánchez García, 2007.
} 


\section{EL PERIODISMO POLÍTICO DE GALDÓS}

La primera «Crónica parlamentaria» de Galdós en Las Cortes fue el 23 de febrero de 1869. La mayoría gubernamental le parecía a Galdós sólida, dispuesta a construir los pilares de la monarquía democrática; mientras que la minoría, el grupo republicano, se dedicaba a la demagogia y a la recriminación, intentando restar legitimidad al proceso revolucionario. Otro tanto le parecían los carlistas. El primer diputado de esta minoría en hablar fue Vinader, y Galdós insistió en su carácter desfasado, antiguo, de quien sacaba a pasear la «antigua fe» con la «ya cascada y enronquecida voz». Su crítica fue muy similar a la que hizo ya en $L a$ Nación, común a la época, ligando el absolutismo con la religión católica. Caracterizaba a los carlistas como profetas del desastre, que con «monjil lloriqueo» hablaban de las "preciosidades arqueológicas», en referencia al catolicismo ${ }^{22}$.

Galdós se identificó entonces con el progresismo democrático de quien pagaba sus artículos, por lo que el primer cambio de gobierno, el 27 de febrero de 1869, le pareció un error porque mantenía a Sagasta, Figuerola, Romero Ortiz, Lorenzana y Ayala; es decir, la parte conservadora. La crítica republicana, indicó, había dejado claro que la economía de Figuerola no servía, ni la interpretación judicial de Romero Ortiz. Sagasta parecía «refractario a la absoluta sanción de los derechos individuales». Echaba de menos a Cristino Martos, al que luego repudió, y concluía:

Estamos en plena democracia: paso a los demócratas. (...). Paso a la democracia, paso a los hombres nuevos, únicos intérpretes de la idea nueva. Abajo todos los elementos gastados, todos aquellos hombres de quienes el país no espera ni puede esperar nada ${ }^{23}$.

Sobraban en el Gobierno, escribió, aquellos que para ser demócratas habían hecho una «abdicación de alma». En esos días, Sagasta y su visión de un progresismo templado no convencía a Galdós. Comenzó criticando que no aboliera la pena de muerte cuando se debatió en las Cortes el 4 de marzo. No se hizo, apuntó, «por un reparo de orden público». Identificaba entonces a Sagasta con el conservadurismo, un recurso muy utilizado por radicales y republicanos. «Parece que tenemos el doctrinarismo infiltrado en la médula de los huesos», sentenciaba. Sagasta no era demócrata. En realidad, le daba miedo la aplicación de los principios.

En vano hablamos mucho de democracia; en vano aparentamos creer que el orden es un resultado de la libertad, y que las perturbaciones sociales se remedian más pronto con la adopción sincera y lógica del sistema democrático; en vano sustentamos de palabra que lo que más agrava las cuestiones de orden público es la

\footnotetext{
22 «Crónicas parlamentarias», Las Cortes, 24 de febrero de 1869.

${ }^{23}$ Las Cortes, 27 de febrero de 1869.
} 


\section{JORGE VILCHES GARCÍA}

restricción y la desconfianza. Estamos en España, el país de los reparos. Temblamos ante la aplicación de lo que creemos y divulgamos. Nos alarman los hechos, mientras declaramos los principios. Nos hemos figurado que somos demócratas y aún no hemos dejado de ser doctrinarios.

Galdós criticó de nuevo a Sagasta, de quien decía, «no entendió esto -en referencia al discurso de Castelar sobre la esencia de la democracia-, como no ha entendido otras muchas cosas». El escritor canario defendió, como hicieron los republicanos, que el desorden podía ser detenido por las instituciones ya existentes, en particular los ayuntamientos. Para reforzar esa idea se reía del partido carlista, «simbolizado por un regio zascandil, bufón de los tronos europeos», y de los isabelinos, de quien decía que no había nada en el mundo «más raro, más exótico y más inverosímil que un isabelino» ${ }^{24}$.

Lo mismo hizo con el general Prim, la «esfinge del ministerio de la Guerra» ${ }^{25}$. Respetaba al general, pero recelaba de su carácter autoritario. «Tampoco nos gustó el general Prim -escribió-. Es muy poco parlamentario eso de que un ministro necesite hacer esfuerzos de liberalismo y de paciencia para oír los fuertes y repetidos ataques de la oposición „ ${ }^{26}$. Criticó de Prim lo mismo que de Sagasta: demócrata en la revolución, conservador en el Gobierno ${ }^{27}$.

Este es el eje sobre el que giran todas las ruedas de la gran máquina política. En la oposición se proclaman los principios, se inician las reformas: se pasa de la oposición al gobierno, y una vez en el banco azul, los principios continúan siendo magníficos, las reformas continúan siendo trascendentales; pero... está de por medio el pero ministerial, esa razón suprema de las carteras, que aplica a toda idea honrada y a todo noble principio el siguiente vergonzoso apodo: irrealizable ${ }^{28}$.

A Galdós le disgustó que el general Prim no aboliera las quintas, tal y como se había prometido en la Revolución. Por esta razón aplaudió el discurso de Fernando Garrido en el que dijo que el Ejército debía disolverse tras la Revolución, porque igual que daba la libertad la podía quitar. «Otra verdad del Sr. Garrido: Si los hombres del Gobierno prometieron la abolición de quintas, creyendo que no podían cumplirlo, han engañado al pueblo» ${ }^{29}$. Esa sospecha sobre el Ejército le acompañó todo este periodo. Llegó a escribir en 1872 que si las instituciones no se asentaban, era posible que llegara una «espada atrevida» ${ }^{30}$. Estuvo siempre

\footnotetext{
${ }^{24}$ Las Cortes, 5 de marzo del 869.

25 «Crónicas parlamentarias», Las Cortes, 23 de febrero de 1869.

26 La cursiva en el texto original.

${ }^{27}$ Es interesante la evolución de la imagen de Prim en Galdós. Ver Ayala Aracil, 2019.

${ }^{28}$ Las Cortes, 7 de marzo de 1869.

${ }^{29}$ Las Cortes, 12 de marzo de 1869

30 «Revista Política Interior», Revista de España [en adelante, RPI, RE], núm. 99, tomo XXV, 10 de abril de 1872 , Pp. 448-459.
} 


\section{EL PERIODISMO POLÍTICO DE GALDÓS}

convencido de la necesidad de que la opinión fuera defendida por partidos civiles, o bien con militares, como Serrano y Topete, que, en su opinión, respetaran las normas $y$ al adversario.

Las opiniones de Galdós eran favorables a la parte demócrata de la coalición de septiembre, y siguiendo la línea del periódico Las Cortes, tendió lazos con los republicanos. No obstante, y al igual que hacían entonces los próceres del partido demócrata como Rivero o Martos, criticaba la radicalidad de los republicanos. Era una desviación que se podía corregir.

Los republicanos en vez de limitarse a pedir la abolición de todo, deberían indicar también los medios de sustituir lo que no les gusta y quisieran ver desterrado. Este sería el modo de presentarse ante el país, no como hombres de oposición tan solo aptos para destruir lo malo, sino como hombres de gobierno, capaces de plantear lo bueno ${ }^{31}$.

Defendió a Figueras, en quien veía un «ángel tutelar» capaz de contener los desvaríos de los republicanos más radicales, y de hacer creer a la nación que los republicanos «son una garantía de orden, una esperanza y una satisfacción de antiguos agravios» ${ }^{32}$. Por otro lado, despreciaba a José María Orense, a quien veía el cabecilla del federalismo revolucionario, colindante con el socialismo. Comenzó haciendo una crítica a los republicanos por filibusterismo, al emplear su tiempo en la tribuna para, escribió el 23 de marzo, «repetir lo que la minoría ha dicho en sus clubes, en sus periódicos, en sus mítines». España, decía Galdós, «reclama su constitución de un modo perentorio», y no estaba para perder el tiempo. Esa necesidad de reformas casaba mal, a su entender, con las «impugnaciones organizadas» por los republicanos, que eran el «mismo elemento corruptor de siempre, la miseria de las cuestiones de personas». En este sentido, Galdós responsabilizaba a Orense, al que llamó «el Pero Grullo de la República» ${ }^{33}$. El ataque al líder federal fue durísimo. Sus palabras eran:

Una serie de recriminaciones amargas, de dudas impertinentes, de recuerdos inoportunos, de sospechas habilidosas, hijas, al parecer, de la tenaz y quisquillosa displicencia de los viejos. Orense es inferior al puesto de honor que por su edad o su experiencia ocupa en el partido republicano. Su oratoria es difusa y atolondrada. Oís por boca suya a un niño de 70 años; de niño, tiene el temor de entrar en profundos razonamientos y en consideraciones graves; de viejo, tiene la nimiedad escrupulosa, el humor impertinente y gruñón. Habla más de sí mismo y de los demás que de sus ideas y de las ajenas ${ }^{34}$.

\footnotetext{
${ }^{31}$ Las Cortes, II de marzo de 1869.

${ }^{32}$ Las Cortes, 16 de marzo de 1869.

${ }^{33}$ Las Cortes, 23 de marzo de 1869.

${ }^{34}$ Las Cortes, 23 de febrero del 869.
} 


\section{JORGE VILCHES GARCÍA}

No fue un gran entusiasta del texto constitucional, sino de la situación constitucional. La Constitución de 1869 no le pareció un libro sagrado, sino el símbolo de la conciliación de los grandes partidos para dar vida a un sistema representativo pacífico, que acometiera en orden las reformas necesarias. Era el fin de un sistema corrupto y decadente como el de la monarquía isabelina, como pensaron muchos, y el inicio de un tiempo nuevo. No obstante, la clave del éxito de la situación dependió, según contó entre 1871 y 1872, del comportamiento de los dirigentes políticos.

\section{DEFENSOR DE LA CONCILIACIÓN LIBERAL}

Peter B. Goldman sostiene que Galdós no empezó a analizar seriamente la vida política hasta la primavera de I87I, momento en que empezó a dirigir El Debate y a escribir la «Revista Política Interior» en la Revista de España ${ }^{35}$. Lo cierto es que durante 1870 se apartó del periodismo político para escribir sus novelas. Su primera preocupación cuando regresó a la prensa fue la política de conciliación, que era la clave del momento ${ }^{36}$.

Tras las elecciones de marzo de I87I, el general Serrano formó un gobierno de conciliación de unionistas, progresistas y demócratas. Esa no era la idea de Prim, quien ya tenía en marcha su Partido Radical, compuesto por estos dos últimos grupos, desde octubre de 1869. La división de la coalición revolucionaria no se había efectuado antes por la interinidad y los ataques de las oposiciones. El propósito de Prim era formar el primer gobierno del reinado de Amadeo de Saboya, con los progresistas y los demócratas, y que mientras se fuera constituyendo un partido conservador con el que alternarse en el poder. Su asesinato truncó este plan y provocó el mantenimiento de la conciliación. Sin embargo, las discrepancias internas entre los tres socios y especialmente entre los dos bandos progresistas, el de Sagasta y Ruiz Zorrilla, hicieron inviable ese ministerio de conciliación. Serrano renunció en julio de 187I, y los radicales formaron gobierno. El de Ruiz Zorrilla duró hasta octubre, y Malcampo, hombre de Sagasta, formó otro después con progresistas templados y unionistas. Estos dos grupos dominaron el gobierno hasta junio de 1872, momento en el que los radicales de Ruiz Zorrilla volvieron al poder.

Entre mayo y julio de $187 \mathrm{I}$, los dos temas de interés de Galdós fueron las dos coaliciones: la de gobierno y la de oposición. Repitió la idea de los unionistas y los progresistas templados sintetizando el pensamiento que Sagasta, ministro

\footnotetext{
${ }^{35}$ Goldman, 1969.

${ }^{36}$ Vilches, 200I, pp. 79-145.
} 


\section{EL PERIODISMO POLÍTICO DE GALDÓS}

de la Gobernación, expresó en el Congreso: los liberales debían mantenerse unidos para conservar las instituciones, consolidar al rey Amadeo, y contener la alianza de las tres oposiciones ${ }^{37}$. La conciliación debía mantenerse. Galdós, inmerso entonces en el estudio de la Historia de España para sus novelas ${ }^{38}$, se remitía a otras épocas de enfrentamiento del «partido liberal» y «las exageraciones», como en el Trienio. Escribió:

Ningún impulso de regeneración se ha verificado en España sin la conciliación de los partidos liberales; todas las catástrofes, todas las horribles reacciones (...) han venido tras la separación de esos mismos partidos ${ }^{39}$.

En julio de 187I la conciliación era reclamada por los conservadores, aunque sin éxito entre los radicales de Ruiz Zorrilla, Rivero y Martos. Estos querían romper la alianza, formar un gobierno monocolor, suyo, alegando que así la administración sería más fuerte y se concluiría la Revolución con las medidas necesarias. No eran del mismo parecer los conservadores. Galdós apoyó esta última opinión en esas fechas, alegando que la composición de las Cortes no lo aconsejaba. El Debate, dirigido por él, achacaba la ruptura de los radicales a las «ambiciones menudas, las impaciencias desordenadas, el personalismo avaricioso de unos cuantos muñidores políticos que sueñan con una cartera ministerial alcanzada a toda costa» ${ }^{40}$.

Lo cierto es que los radicales no tenían una mayoría parlamentaria suficiente como para no depender de nadie y, por tanto, serían víctimas del filibusterismo. El Gobierno de Serrano, de conciliación, había sido un «ministerio de resistencia y de transacción», más que «organizador y activo» para detener a las oposiciones. No era momento para el «deslinde de campos» ante una Cámara compuesta de «diversas y contradictorias tendencias, en medio de un océano de pasiones, teniendo que luchar con la demagogia, defensora de la Commune, y con el viejo absolutismo, resucitado en los comicios inopinadamente» ${ }^{41}$.

La conciliación tenía el objetivo, decía Galdós, de afianzar a la dinastía Saboya frente a los ataques de republicanos y carlistas. Denunció entonces las «frívolas patrioterías» con las que los «fanáticos escritores» de esos dos partidos quisieron despreciar a Amadeo I por no ser español. Hablaron de la indignidad que era para España aceptar un rey extranjero, sacando ejemplos de la historia con «disimulada malevolencia». A pesar de estas palabras, Galdós defendió a la

\footnotetext{
${ }^{37} \mathrm{RPI}, \mathrm{RE}, 77, \mathrm{XX}, 10$ de mayo de $187 \mid$, pp. $|3|-\mid 40$.

${ }^{38} \mathrm{En}$ El Debate del 18 de julio de $187 \mathrm{I}$ se lee: «La nuestra de puro entretenida especialmente en el presente siglo, más que historia parece novela».

${ }^{39}$ El Debate, 18 de julio de 187 I.

${ }^{40}$ El Debate, 2 I de julio de 187 I.

${ }^{41}$ RPI, RE, 80, tomo XX, 25 de junio de I87I, pp. 627-637.
} 


\section{JORGE VILCHES GARCÍA}

nueva dinastía como expresión de la conciliación revolucionaria, al igual que otros escritores o historiadores de la época, como es el caso de Antonio Pirala. El canario se dedicó más a sostener la situación revolucionaria de la cual el nuevo rey era una pieza más. En eso también se sumó al sentir general de los partidos revolucionarios. No hubo un «amadeísmo», sino un apoyo circunstancial e instrumental. Se trataba más de la defensa de la figura del rey de la revolución, como llegó a titular luego, que de la persona o la dinastía. No hubo ningún arraigo popular de Amadeo, y de eso intentaron aprovecharse republicanos y carlistas. De ahí que Galdós dijera que había sido la conciliación de unionistas, progresistas y demócratas tras la muerte de Prim la que

salvó y afianzó la dinastía, combatida por tantos y tan diversos enemigos, atacada con armas de todas clases, desde el proceso político e histórico pronunciado por el tribuno, hasta la vil calumnia, proferida por gentes hechas a todas las torpezas ${ }^{42}$.

La línea de Sagasta en I87I era mantener la conciliación entre los tres partidos de la revolución, ya fuera con un gobierno conjunto o con un programa. Por eso no admitió el plan de Ruiz Zorrilla de fusionarse con los demócratas y dejar fuera a los unionistas, y no quiso aceptar un par de ministerios en su Gobierno. Ruiz Zorrilla presentó en julio un Ejecutivo radical.

La crisis del progresismo sin Prim hizo que en octubre de 187/ el partido estuviera definitivamente roto. Ruiz Zorrilla se decía líder del Partido Radical, unido a los demócratas, y que tendía a la alianza con el Partido Republicano. No en vano cobijaba el plan de formar en el futuro «el gran partido liberal» entre estos tres, contando con el republicanismo moderado de Castelar. Sagasta, sin embargo, creía que podía reconstruir el Partido Progresista bajo su liderazgo, lo que suponía despreciar a los unionistas y demócratas, e intentar recuperar a los progresistas que se habían ido con Ruiz Zorrilla. Amadeo de Saboya, auxiliado por José Luis Albareda, puso orden, e instó a dar el poder a una mayoría parlamentaria dinástica siempre que fuera un partido, no una facción. Esto obligó a Sagasta a decidirse por la fusión con la Unión Liberal, y empujó a Ruiz Zorrilla a separarse del rey, de sus antiguos compañeros de Revolución, y a acercarse a los republicanos. Por eso, fue Ruiz Zorilla quien impulsó la llamada «coalición nacionalı junto a los carlistas, moderados y federales para ir juntos a las elecciones $y$ derrotar a Sagasta en los comicios de abril de 1872.

Galdós echó la culpa de la ruptura de la conciliación en julio de $187 \mathrm{I}$ a los radicales, quienes, a su entender, creyeron la propaganda republicana, y llamaron a Topete, Sagasta y Malcampo, escribió, «traidores y reaccionarios». Fue entonces cuando se perdió la creencia de que las instituciones se asentaban en la

\footnotetext{
${ }^{42} \mathrm{RPI}, \mathrm{RE}, 93$, tomo XXIV, 10 de enero de 1872, PP. I45-152.
} 


\section{EL PERIODISMO POLÍTICO DE GALDÓS}

cooperación entre los partidos de la revolución. Galdós hizo una crítica dura del viejo Partido Progresista, a quien achacaba el «poner en peligro las cosas más sagradas». Su disgregación había sido, dijo, por motivos personales, no por «obra de las ideas». De esa división no podía salir un «turno pacífico», sino el «espantoso desorden moral en que vivimos», escribió a principios de 1872. Los obstáculos tradicionales, apuntó en referencia a la famosa frase de Salustiano de Olózaga para referirse a los impedimentos que Isabel II ponía para llamarles al Gobierno, ya no existían, y aun así el progresismo era incapaz de dejar atrás una «sensibilidad rebelde y desenfrenada» ${ }^{43}$.

En esta etapa Galdós dejó demostradas las preferencias por los demócratas en sus artículos para Las Cortes de 1869. Ahora eran a sus ojos una facción peligrosa para el sistema en tanto estrechaban lazos con el republicanismo y despreciaban a los conservadores. El contraste entre las opiniones de 1869 y las de I87I es llamativo. Esto pudo deberse a que por aquel entonces Galdós recuperó su tendencia al progresismo templado expresado en La Nación entre I 865 y I868, o que su estudio de la historia de España, tal y como apuntó en varias ocasiones, le hiciera rechazar las posturas exageradas para asentar una situación liberal. También existe una tercera posibilidad, y es que Galdós, tras un año 1870 con menos ingresos, aceptara las posiciones políticas de José Luis Albareda.

\section{A FAVOR DE LA FUSIÓN CONSERVADORA}

Entre julio y diciembre de 187I hubo cuatro gobiernos, presididos por Serrano, Ruiz Zorrilla, Malcampo y Sagasta. Amadeo I no tuvo más remedio que acceder a la disolución de las Cortes, y entregar a Sagasta el decreto de convocatoria electoral. Era evidente, como así fue, que precisaba de mayorías parlamentarias sólidas que asentaran la monarquía democrática de la Constitución de 1869. La decisión del rey con un «memorándum» leído en Consejo de Ministros -el «papelito» que le escribió Albareda-, había sido acertada contribuyendo a «acelerar la fusión» ${ }^{44}$. No podía dar el decreto a los radicales porque hubiera sido sancionar la labor de oposición, e indicio de preferencia por los de Ruiz Zorrilla. Hubiera perdido, remató Galdós, la «serena imparcialidad y rectitud que ha mostrado la Corona en todos sus actos». El escritor mostraba así una correcta interpretación de la teoría del poder moderador en monarquías constitucionales, entendiendo al Jefe del Estado como árbitro imparcial entre los partidos e instituciones. En realidad, fue la conducta que siguió Amadeo de Saboya desde el

\footnotetext{
${ }^{43} \mathrm{RPI}, \mathrm{RE}, 93$, tomo XXIV, 10 de enero de I872, pp. I45-I52.

44 «Crónica de la quincena», La llustración de Madrid. Revista de política, ciencias, artes y literatura, III, 52, 29 de febrero de 1872, pp. 50-52.
} 


\section{JORGE VILCHES GARCÍA}

comienzo de su reinado, intentando mediar entre los dirigentes y sus conflictos, sin decantarse por nadie.

Los argumentos de Galdós en aquellos meses coincidieron con los expresados por los políticos y periódicos de los unionistas de Serrano y los progresistas de Sagasta. El escritor vio con preocupación la deriva republicana de los radicales, impulsada por Cristino Martos, mientras echaba en falta el sentido común que se atribuía a Ruiz Zorrilla. A esto se unía la inviabilidad de un Congreso en el que la unión de republicanos y carlistas en el filibusterismo hacía muy difícil la vida parlamentaria, y, dijo, «entorpecía todo gobierno». Los radicales creyeron que los conservadores eran un obstáculo, que solamente un gobierno de partido, no de coalición, podría acometer con rapidez las reformas necesarias. Todo era culpa, escribió, de

los corifeos del absolutismo y de la república socialista, en cuyas manos estaba la decisión de los grandes negocios, usaban de su omnipotencia legislativa con un desenfado burlón y cínico que impulsaba a aborrecer el sistema representativo ${ }^{45}$.

Republicanos y carlistas habían entorpecido el sistema parlamentario y alimentado la ambición del Partido Radical, escribió Galdós en numerosas ocasiones. Eran dos movimientos que se habían convertido en un obstáculo contra la libertad. Gran parte de sus textos de I87I y 1872 están dedicados a atacar la coalición de oposición que formaron republicanos, carlistas y moderados. Estos tres fueron juntos a las elecciones de marzo de I87I. Quisieron que los comicios se convirtieran en un plebiscito sobre la monarquía de Amadeo. Su propósito era sacar mayoría en el Congreso e impugnar el régimen. Fracasaron. Aprobadas las actas, los tres grupos opositores funcionaron juntos en las Cortes: mantenían reuniones antes de las sesiones para decidir temas y votaciones. En realidad, era una continuación de la alianza durante las Cortes constituyentes ${ }^{46}$. El Debate lo llamaba «Pacto de las Oposiciones», aunque, como muy bien señaló José Luis Albareda, quedaban fuera de esa alianza los liberal-conservadores de Cánovas.

La idea de Galdós respecto al carlismo era bastante corriente. No distinguía entre absolutismo, tradicionalismo, neocatolicismo y carlismo, sino que lo agrupaba todo bajo la etiqueta de «reacción», a no ser que resaltar sus divisiones le valiera para desacreditarlos. Así, en I87I relataba la diferencia entre los neocatólicos de Cándido Nocedal, que preferían el parlamentarismo, y los viejos carlistas, con su «rudeza primitiva». Eran estos últimos, decía, los que querían que Don Carlos organizara mejor su «hueste sagrada» para ir a la guerra ${ }^{47}$. El

\footnotetext{
${ }^{45} \mathrm{RPI}, \mathrm{RE}, 95$, tomo XXIV, 10 de febrero de I872, pp. 452-460.

${ }^{46}$ Vilches, 2015 y 2020.

${ }^{47} \mathrm{RPI}, \mathrm{RE}, 77$, tomo XX, 10 de mayo de I87|, PP. I3|-|40.
} 


\section{EL PERIODISMO POLÍTICO DE GALDÓS}

carlismo, en su opinión, solo tenía fuerza porque una parte de la Iglesia estaba detrás y empujaba a los fieles. Galdós no ahorraba insultos a los carlistas, no solo a sus dirigentes, sino también a sus seguidores, que eran «infelices secuaces de última fila, la multitud catedral y parroquial» ${ }^{48}$.

Como hicieron muchos escritores e historiadores del momento, Galdós señalaba a los revolucionarios de 1868 como los herederos de 1812 y 1820 , mientras que los carlistas eran la reacción, los mismos de 1814, 1823 y de las guerras civiles. En sus críticas periodísticas se notan sus lecturas para escribir sus primeras novelas, «El audaz» y «La Fontana de Oro», nutriéndose evidentemente de las obras liberales. El carlismo, por tanto, era una fuerza fuera de su tiempo y derrotada, que insistía en entorpecer el progreso del país. «El absolutismo -escribió en 1872 - que desde mucho antes había perdido la batalla en el terreno filosófico, fue también vencido por la fuerza» 49 . El liberalismo había desmontado el entramado absolutista con la desamortización civil y eclesiástica, las obras públicas, la administración y la propaganda. La reacción frente a este progreso fueron «intentonas descabelladas», como la que se produjo en el verano de 1869 y en mayo de $1872^{50}$. El problema no era la gente, «infelices mozos de campo», sino la «sugestión religiosa». Era el «fanatismo clerical» lo que llevaba a la guerra civil. La solución, por tanto, escribía Galdós tras el alzamiento carlista del 2 de mayo de 1872, era el «arreglo del clero y una modificación juiciosa de las instituciones forales», donde había sobrerrepresentación del mundo rural, que era más clerical que el urbano ${ }^{51}$. En su línea liberal-conservadora de aquellos días, Galdós aplaudió el convenio de Amorebieta, que establecía una frágil paz, defendiendo al gobierno del general Serrano 52 .

La fusión conservadora se produjo en abril de 1872, prácticamente obligada por el rey y las circunstancias. Esa fusión iba a ser, escribió Galdós, «utilísima y salvadora». El objetivo era acabar con el filibusterismo parlamentario y el desorden público creado por carlistas y republicanos. Eso no era reaccionario, aunque así lo dijeran los radicales. Tal acusación se debía, a su entender, a que la oposición no podía «renunciar a la explotación de esa mina oposicionista» que consistía «en acusar constantemente de reaccionario al poder público». El programa que había presentado el Gobierno en las Cortes a través del discurso de la Corona mostraba con claridad lo que llamó «política conservadora constitucional» ${ }^{53}$.

\footnotetext{
${ }^{48} \mathrm{RPI}, R E, 80$, tomo $X X, 25$ de junio de I87I, pp. 627-637.

${ }^{49} \mathrm{RPI}, R E, 102$, tomo XXVI, 25 de mayo de I872, pp. 292-300.

${ }^{50} \mathrm{RPI}, R E, 102$, tomo $X X \mathrm{VI}, 25$ de mayo de 1872, Pp. 292-300.

${ }^{51} \mathrm{RPI}, \mathrm{RE}, 10 \mathrm{I}$, tomo XXVI, 10 de mayo de 1872, PP. I36-I42.

${ }^{52}$ Sobre la visión de Galdós acerca de la primera guerra carlista, Ayala Aracil, 2016.

${ }^{53} \mathrm{RPI}, \mathrm{RE}, 100$, tomo XXV, 25 de abril de I872, PP. 6II-62I.
} 


\section{JORGE VILCHES GARCÍA}

Galdós incluso se atrevió a definir con elogios el objetivo del Partido Conservador. Se trata de que la sociedad española viera que podía existir la libertad establecida por la Revolución sin que hubiera desorden social. Consistía en convencer a esa «mayoría callada, paciente, razonable, tan enemiga de la perturbación como de la arbitrariedad». Ese debía ser «el punto objetivo del Partido Conservador». Era tiempo, escribió, de dicho partido porque había «necesidad de reposo», «algún tiempo de calma» en las Cortes y en las calles para dar «consistencia» a «algunas instituciones democráticas» ${ }^{54}$. Tan deplorable era la indiferencia del pueblo al riesgo de perder la libertad, como el «terrible encarnizamiento» de la lucha entre partidos solo para conseguir «el triunfo de sus principios» ${ }^{55}$. Era necesaria una etapa de moderación apoyada por esos españoles que querían paz.

La justificación de que era el momento del Partido Conservador no era suficiente, sino que consideraba que los españoles no tenían costumbres públicas liberales, y requerían un gobierno fuerte. Ese era el problema de la libertad en España, la falta de compromiso de los españoles con el respeto a las normas liberales ${ }^{56}$. Los españoles tenían más empeño en conquistar la libertad que en mantenerla. «Este es uno de los obstáculos con que tropieza y tropezará por mucho tiempo aquí el gobierno representativo», escribió. El español estaba acostumbrado a que todo llegara del Gobierno. «El ciudadano, acostumbrado por el absolutismo a que se lo den todo hecho, se cruza de brazos esperándolo todo del poder». El español no piensa que hubiera que vigilar la libertad continuamente:

Sabe derrocar la tiranía, sabe conquistar el derecho y la libertad; pero pronto se cansa de ejercer aquel y apenas tiene idea de cómo se conserva esta. No comprende que la práctica del gobierno por la nación misma exige una vigilancia constante y una firme entereza en el cumplimiento de los deberes políticos.

Hacía falta un gobierno conservador que hiciera entender a los españoles que cada persona es «árbitro de sus propios destinos», y que la libertad se podía perder. Era necesario que pasara tiempo, con elecciones y parlamentos, para que la libertad se asentara con firmeza en España. La adquisición finalmente de costumbres públicas liberales, escribió, «apartará al país de extremos tan funestos como son la lucha desordenada y sangrienta, o el retraimiento y la indiferencia» ${ }^{57}$. No obstante, en junio de 1872 Galdós consideraba que, dada la excitación del

${ }^{54} \mathrm{RPI}, \mathrm{RE}, 96$, tomo XXV, 25 de febrero de 1872, pp. 608-6I5.

55 «Crónica de la quincena», La llustración de Madrid. Revista de política, ciencias, artes y literatura, año III, 54, 30 de marzo de 1872, pp. 82-83.

${ }^{56}$ Aquí Galdós recogió la interpretación de la revolución liberal que hicieron los moderados puritanos, luego liberal-conservadores, como Nicomedes Pastor Díaz, Andrés Borrego, o incluso Cánovas. De hecho, El Debate llamaba «partido liberal-conservador» al de Serrano y Sagasta.

${ }^{57} \mathrm{RPI}, \mathrm{RE}, 99$, tomo XXV, 10 de abril de 1872, pp. 448-459. 


\section{EL PERIODISMO POLÍTICO DE GALDÓS}

radicalismo y el republicanismo y la ausencia de costumbres públicas, «el ejército es hoy el único elemento de orden que queda a esta desamparada sociedad». Esa institución era, a su juicio, la única capaz de mantener las conquistas revolucionarias en $\mathrm{paz}^{58}$.

\section{LOS RADICALES SON EL PROBLEMA}

El problema para Galdós comenzó a ser el Partido Radical, según sus artículos en la Revista de España. El comportamiento y el discurso de los radicales eran demasiado parecidos a los de los republicanos, en una oposición sistemática al partido conservador-constitucional de Serrano y Sagasta. El comportamiento del rey, escribió, había sido el correcto. No podía mantenerse un Congreso con una oposición que impedía la acción del Gobierno. Amadeo entregó los decretos de disolución y convocatoria electoral a Sagasta, y la deriva revolucionaria del partido radical se desató. Ruiz Zorrilla pronunció en el Congreso un discurso a favor del «derecho de insurrección», y la prensa radical comenzó a atacar al rey.

Los comicios fueron convocados para abril de 1872. Los radicales debatieron entonces si ir al retraimiento o coaligarse con republicanos y carlistas para desbaratar los «obstáculos tradicionales». Rivero lo propuso en la reunión del Partido el 2 de febrero, pero se desechó. La decisión fue ir a las elecciones con carlistas y republicanos; de hecho, ya habían ido con estos últimos a las elecciones municipales de diciembre de I87I, que tomaron como un plebiscito contra el Gobierno y perdieron. La junta directiva del Partido Radical, a cuyo frente estaba Ruiz Zorrilla, ofreció ir en coalición electoral a republicanos, carlistas y moderados con el nombre de «coalición nacional».

Galdós vio en el retraimiento propuesto por Rivero la maniobra de un pequeño grupo, el demócrata, que quería ocultar su derrota con esa maniobra. Su crónica de esa reunión fue tan irónica como despectiva, todo en defensa de Sagasta ${ }^{59}$. Por otro lado, la coalición nacional — «grotesco nombre», escribióera «criminal» porque quería llevar a las Cortes a quienes eran incompatibles con la Constitución. Esa «negación espantosa» era la antesala de «la más sangrienta y encarnizada lucha que ha presenciado España». Galdós hizo campaña por el Partido Conservador, por lo que al tiempo que encomió su necesidad, se dedicó a desprestigiar a sus adversarios y a anunciar que su victoria sería el anuncio de una guerra. Lo cierto es que no le faltó razón: los carlistas se levantaron en armas según terminaron las elecciones y los republicanos planearon una insurrección

\footnotetext{
${ }^{58} \mathrm{RPI}, \mathrm{RE}, 104$, tomo XXVI, 25 de junio de I872, pp. 608-6I6.

${ }^{59} \mathrm{RPI}, \mathrm{RE}, 95$, tomo XXIV, 10 de febrero de I872, PP. 452-459.
} 


\section{JORGE VILCHES GARCÍA}

en octubre de ese año60. También acertó cuando a principios de marzo explicó que los radicales habían confundido Madrid con España, y que los republicanos y carlistas de provincias en ningún caso votarían unos por otros. Galdós consideraba que los españoles darían la espalda a unos firmantes que se habían movido por el «odio personal, la envidia, el escepticismo». En definitiva, era una «coalición negativa» que parecía «la misma locura». El desprecio de Galdós a esa coalición fue tan evidente, que hasta en La llustración de Madrid, donde no debía haber «ningún discorde ruido de la política», escribió que contenía «tendencias tan pavorosas, que ponían miedo en los corazones de los más despreocupados y aventureros» ${ }^{61}$.

El Partido Radical podía haber esperado su turno, como dijo Sagasta a la comisión de dicho partido en diciembre de I87I, y así lo repitió Galdos en sus artículos. El radical podía haber sido un «partido útil, poderoso» que «hubiera sustituido en la ocasión oportuna al conservador», consiguiendo así la «ansiada armonía constitucional». Sin embargo, escribió, había caído a la «profunda sima de su locura». El Partido Radical no quería el poder, sino venganza, y por eso había iniciado una coalición que solo podía destruir la monarquía democrática. Había pactado con los «ebrios comunistas», los «fanáticos trabucaires de D. Carlos», «los aristócratas», «los demagogos desahuciados, los alfonsinos sentimentales, los carlistas incultos y fanáticos». Era una ironía que se quisiera salvar la libertad aliándose con los «enemigos de la monarquía, los enemigos de la religión, los enemigos de la libertad y los enemigos de la propiedad». Si llegara la República, escribió en la temprana fecha de marzo de 1872, los radicales «recibirían un puesto de segunda fila», como ocurrió. La crítica a Ruiz Zorrilla fue muy dura. Un hombre monárquico y liberal no podía pactar con carlistas y republicanos. El mismo progresista que había ido a recoger a Amadeo de Saboya a Florencia no respetaba sus decisiones, o era que por una «insensata ambición» quería convertir al rey en «jefe exclusivamente del partido radical». La formación de la llamada «coalición nacional», en opinión de Galdós inhabilitaba a Ruiz Zorrilla, no ya para jefe de un partido, escribió, sino de una «pequeña pandilla con pretensiones de influir en los destinos públicos, y mucho menos para ocupar el poder» ${ }^{62}$.

El resultado de las elecciones de abril de 1872 fue muy malo para el Partido Radical, que quedó como tercero de la cámara. Había quedado «tan corrompido, tan ciego, tan escéptico, que ni él mismo sabe hasta dónde será arrastrado por las pasiones propias y las intrigas extrañas». La victoria radical en Madrid se debió

\footnotetext{
${ }^{60} \mathrm{RPI}, \mathrm{RE}, 95$, tomo XXIV, 10 de febrero de I872, pp. I45-I52.

${ }^{61}$ "Crónica de la quincena», La llustración de Madrid. Revista de política, ciencias, artes y literatura, año III, 53, 15 de marzo del872, pp. 66-67.

${ }^{62} \mathrm{RPI}, \mathrm{RE}, 97$, tomo XXIV, 10 de marzo del872, pp. I27-I40
} 


\section{EL PERIODISMO POLÍTICO DE GALDÓS}

a dos factores, dijo Galdós. Por un lado, su prensa atemorizó a los electores diciendo que habría violencia en la capital entre el 3 y el 5 de abril, días de los comicios, con una «función pirotécnica a estilo comunista» ${ }^{63}$. Eso hizo que mucha gente no saliera de su casa. Lo cierto es que la abstención rozó el $60 \%$ en la capital. Por otro lado, los alcaldes de barrio, nombrados por el alcalde radical de Madrid, movilizaron a los empleados públicos y a quienes dependían del dinero municipal.

Por esta razón se vio que de la noche a la mañana se trocaron en devotos zorrillistas muchísimos individuos de los que se dedican a satisfacer las múltiples necesidades de la villa en varios ramos de comercio o servicios públicos, distinguiéndose por su celo en pro de la coalición aquellos que, por algún desliz u olvido de las pragmáticas municipales, tenían motivos para desear estar bien con el alcalde de barrio. A estos se unían ejércitos de braceros, ocupados en las obras del ayuntamiento, y que de pronto se sintieron unánimemente afectados de un delirante amor a la causa nacional ${ }^{64}$.

Los radicales, derrotados, hablaron de insurrección y de retraimiento. Galdós no dejó pasar la ocasión para denunciar esta deriva de los radicales. En su afán por defender al Gobierno conservador, denunció que el retraimiento era un instrumento de perdedores. Así lo decía:

El retraimiento es siempre el procedimiento natural de la desesperación política: jamás se adopta con objeto de alcanzar el gobierno dentro del régimen vigente a la sazón, es camino que lleva la contienda suprema con los poderes inveteradamente repulsivos al país, y no concluye sino con grandes cataclismos, seguidos del imperio franco y desenmascarado de la fuerza, o del triunfo completo de la liber$\operatorname{tad}^{65}$.

Entendió que era desproporcionado que dicho partido se hubiera unido a carlistas, moderados y republicanos contra sus antiguos socios revolucionarios, y que no había motivo para anunciar el retraimiento en junio de 1872 . El ejercicio de las libertades, escribió, es pleno; de hecho, esos cuatro partidos se habían presentado a las elecciones, sus periódicos seguían en la calle, y sus voces eran oídas en las Cortes. Galdós insistía en la sinrazón de la política de oposición del radicalismo, de la que culpaba a Ruiz Zorrilla. El problema estaba, según Galdós, en que esos radicales habían abandonado a los conservadores, prefiriendo la compañía en especial de los republicanos.

${ }^{63}$ «Crónica de la quincena», La llustración de Madrid. Revista de política, ciencias, artes y literatura, año III, 57, 15 de mayo de 1872, Pp. 138-139.

${ }^{64} \mathrm{RPI}, R E, 99$, tomo XXV, 10 de abril de 1872, pp. 448-459.

${ }^{65} \mathrm{RPI}, \mathrm{RE}, \mathrm{I02}$, tomo XXVI, 25 de mayo del872, Pp. 292-300. 


\section{JORGE VILCHES GARCÍA}

La invitación de Emilio Castelar a una actitud «benevolente», de colaboración con un gobierno radical, había ahondado las diferencias entre los antiguos socios de revolución. Además, eso había abierto una alianza entre radicales y republicanos que muchos vieron como un peligro para la monarquía democrática. No en vano una parte del radicalismo declaró que no vería mal una República. De hecho, Nicolás María Rivero, uno de los grandes referentes de la democracia, dijo desde el principio del proceso revolucionario que era un «monárquico circunstancial». Esto significaba que la República era su forma ideal de Estado, pero que apoyaría la monarquía democrática mientras siguiera en la senda reformista y en sus manos. En realidad, prácticamente todo el Partido Radical se había pasado al republicanismo. Galdós consideraba que a no tardar se proclamaría la República porque era la consecuencia lógica para los radicales. Galdós denunciaba que los radicales ya tenían pactado con los republicanos un cambio de régimen, que a la coalición electoral le seguiría una acción conjunta para ir a la República. No hay que olvidar que en la mañana del II de febrero todos los diputados y senadores radicales votaron a favor de la República, y dejaron a Ruiz Zorrilla solo. Galdós sabía esto desde las elecciones de abril de 1872 y por eso decía sobre Ruiz Zorrilla:

Nosotros, a pesar de la incalificable torpeza de la coalición, tenemos idea mucho más alta de él, y no le creemos capaz de prestar su nombre ni su iniciativa para incubar en pocos días una republiquilla enana, grotesco mensajero de la restauración borbónica ${ }^{66}$.

\section{ANTES DE TRAFALGAR}

Galdós abandonó el periodismo político en agosto de 1872. Quizá fue por lo que señalaba el artículo de fondo de El Debate a principios de ese mes: los conservadores ya no podían esperar nada de un régimen en el que el rey había dado el poder a unos radicales que pactaban con los republicanos, y repudiaban a los constitucionales ${ }^{67}$. El periódico dirigido por Galdós defendió el retraimiento del Partido Conservador para las elecciones de agosto de 1872, para que Amadeo de Saboya comprendiera «el vacío horrible en que se vive cuando se vive solo con los radicales» ${ }^{68}$. El Debate se dedicó a criticar al Gobierno radical, sus Cortes y las leyes que de ellas salieran. Sin embargo, Galdós dejó la dirección del periódico el 6 de octubre. Lamentablemente no sabemos qué pensó de la crisis de la monarquía de Amadeo de Saboya, del fracaso de Ruiz Zorrilla —que él

\footnotetext{
${ }^{66} \mathrm{RPI}, \mathrm{RE}, 103$, tomo XXVI, 10 de junio de 1872, pp. 457-466.

${ }^{67}$ «Situación de las clases conservadoras», El Debate, 10 de agosto de 1872.

${ }^{68}$ El Debate, 26 de agosto de 1872
} 


\section{EL PERIODISMO POLÍTICO DE GALDÓS}

predijo-, ni del advenimiento de la República en febrero de 1873 y el cantonalismo. En ese tiempo Galdós estuvo dedicado a la literatura. El 25 de febrero de 1873 apareció un texto suyo en la Revista de España. Hubiera sido el número ideal para hacer una crónica histórica sobre los acontecimientos políticos, sin embargo, el texto se titulaba «Antes de Trafalgar (páginas de una novela)». En una nota a pie de página explicaba que se trataba de un adelanto del primer libro de los «Episodios Nacionales».

No analizó la situación, ni opinó entonces, pero sí sabemos qué dijo de los republicanos antes de la República de 1873. Los republicanos no le merecieron a Galdós durante el reinado de Amadeo I la misma consideración que en tiempos de las constituyentes, según había escrito en el diario demócrata Las Cortes. Una vez elegido rey, el canario se decantó sin ambages por la defensa de la monarquía amadeísta y dentro de las ideas liberal-conservadoras. Los republicanos habían cometido para Galdós dos errores: unirse a los carlistas y aceptar «en parte o en conjunto los actos de la Comuna» ${ }^{69}$.

Galdós vinculó el republicanismo con el socialismo, y de ahí la relación que estableció entre el episodio de la Comuna de París y los federales españoles. Denunciaba Galdós en la primavera de 187 I que los republicanos habían tomado el socialismo con simpatía, incluso Emilio Castelar. El propósito de los dirigentes del republicanismo español era, decía, «allegar el voto de las muchedumbres, incensando la bárbara e inmoral insurrección de París». Escribió que la violencia en París encajaba «bien con el carácter y tendencias de los habitantes de ciertas localidades de Españay. La posición favorable a la Comuna era una de las causas que más contribuían «al deshielo de la oposición federal, que cada día pierde terreno en las comarcas y en las ciudades» ${ }^{70}$. Esa búsqueda del voto de los desheredados, había hecho que en la dirección republicana «los federales sensatos e inteligentes» hubieran "cedido el puesto a los comunistas» ${ }^{71}$. Los republicanos querían desestabilizar las instituciones y llevar la revolución a España. Por eso habían aceptado la «coalición nacional» con los carlistas y moderados, porque el desorden

ofrece una probabilidad de gran precio a los que sueñan con recoger el poder en las calles ensangrentadas, cuando todo yace por el suelo, y la sociedad conmovida de espanto cede al yugo de sus mayores enemigos ${ }^{72}$.

\footnotetext{
${ }^{69} \mathrm{RPI}, \mathrm{RE}, 80$, tomo XX, 25 de junio de I87I, pp. 627-637.

${ }^{70} \mathrm{RPI}, \mathrm{RE}, 77$, tomo XX, 10 de ,mayo de I87I, Pp. I3I-I 40.

71 RPI, RE, 97, tomo XXIV, 10 de marzo de I872, PP. I27-140.

${ }^{72} \mathrm{RPI}, \mathrm{RE}, 97$, tomo XXIV, 10 de marzo de I872, PP. I27-I40.
} 


\section{JORGE VILCHES GARCÍA}

Aprovechaba también Galdós para criticar el socialismo y La Internacional, que era a su entender quien había inspirado la Comuna. Su propagación por España, decía, «ha alarmado a todas las personas sensatas». Los internacionalistas eran un obstáculo para el desarrollo de la monarquía democrática en España, «iniciada con felicidad». Este «mal», el del socialismo, no presentaba entre los españoles «los caracteres de gravedad» que se observaban en otros países. Las muchedumbres eran engañadas por los socialistas, que las adulaban con falsas promesas de prosperidad y riqueza «no adquiridas por medio del trabajo», de «bienes sin cuento» ${ }^{73}$. Aun así, concluía, era un problema que no debía mirarse con la «desdeñosa indiferencia que aquí suele aplicarse a todos los peligros incipientes».

Ese abandono del republicanismo al socialismo y a la violencia haría imposible la República. El federalismo había «insultado a la clase media» en «nombre del cuarto estado». La República iba a llegar, pero ninguno de sus cuatro líderes, escribió, iba a tener la capacidad para gobernarla. Ni Castelar con su «arpa de oro», ni $\mathrm{Pi}$ «con su profundidad de entendimiento y su lógica terrible», ni Figueras «con su fogosidad parlamentaria», ni aún Salmerón «que enunciando en misteriosas fórmulas filosóficas las ideas de emancipación social parece como el apóstol que ha de convencer a todas las gentes». Ninguno de esos cuatro, escribió Galdós en la temprana fecha de marzo de 1872, «durará mucho tiempo sobre los escabeles en que los puso la opinión republicana» ${ }^{74}$. Tenía razón.

La República sería un fracaso, escribió, una «triste, menguada e irrisoria república». La aspiración republicana era la fórmula que parecía arreglarlo todo, pero era la ilusión creada por la «propaganda de hombres rencorosos y alucinados». No había costumbres públicas liberales porque los republicanos habían construido su acción y discurso político sobre la falta de respeto a la ley, la deslegitimación de las instituciones, la creencia de que eran una minoría que podía imponer a los demás un régimen. Han sido, sentenció, «ateos de la ley». A esto sumaba que las ideas federales habían sufrido una «sorda invasión» por las ideas socialistas, por lo que el desorden estaba asegurado. Se lanzaría en España la «democracia roja, que ebria de sangre y de goces materiales», aspiraba a reformar la sociedad, poniéndola «al nivel de su grosera ignorancia y torpes pasiones». No había tampoco un Washington, un Cromwell, «ni siquiera un Robespierre» que la dirigiera. Esa República sería una «bochornosa saturnal», un «paseo sangriento y tabernario» que España no viviría «más tiempo del que necesitara la sociedad para reponerse de la primera impresión de pavor» ${ }^{75}$. No se equivocó.

\footnotetext{
${ }^{73} \mathrm{RPI}, \mathrm{RE}, 77$, tomo $X X, 10$ de mayo de I87I, Pp. I3I-|40.

$74 \mathrm{RPI}, \mathrm{RE}, 98$, tomo $X X \mathrm{XV}, 25$ de marzo de I872, pp. 286-298.

${ }^{75} \mathrm{RPI}$, RE, I00, tomo XXV, 25 de abril de I872, Pp. 6II-62I; y RPI, RE, 97, tomo XXIV, 10 de marzo de I872, Pp.
} 


\section{EL PERIODISMO POLÍTICO DE GALDÓS}

\section{CONCLUSIÓN}

Galdós respondió a las ideas del medio que pagaba sus escritos, por lo que se demostró demócrata con simpatía republicana en Las Cortes, liberal conservador en la Revista de España y El Debate, y cínico en La llustración de Madrid. Del mismo modo, se ensañó con quienes consideraba enemigos de las ideas que defendía en cada momento. La única línea continua fue el ataque al carlismo, tal y como ya hizo en La Nación antes de I868, y al final de su vida. En su etapa en Las Cortes fueron objeto de sus críticas los conservadores, mientras que en el tiempo que trabajó en las publicaciones de Albareda fueron los republicanos, carlistas y radicales. Es probable que dicho vaivén en tan poco tiempo provocara el silencio que guardó en su vejez respecto a sus colaboraciones periodísticas durante el Sexenio, ya que gran parte de sus análisis y expresiones perjudicaban su imagen de republicano y simpatizante del socialismo.

\section{BIBLIOGRAFÍA}

Abella Poblet, Manuel y Alfonso García Escuder, «La llustración de Madrid, nuestro ilustre antepasado», Ilustración de Madrid: revista trimestral de la cultura matritense, I7, 2010, pp. 87-92.

Andrades Ruiz, María Ascensión, Los artículos costumbristas de Benito Pérez Galdós en La Nación y la influencia de los mismos en sus Novelas de la Primera Época (Retrato de la sociedad madrileña del siglo XIX), Madrid, Universidad Complutense, 2003.

Arencibia, Yolanda, Galdós. Una biografia, Barcelona, Tusquets, 2020a

Arencibia, Yolanda, «"Hechos, nada más que hechos”: últimas crónicas del periodista Galdós», Monteagudo, 25 2020b, pp. 65-74.

Ayala Aracil, María de los Ángeles, «La primera guerra carlista a través de la mirada de Larra y Galdós», La historia de la literatura española del siglo XIX, ed. José Manuel González Herrán et al., Barcelona, Universitat de Barcelona, 2016, pp. 191-203.

Ayala Aracil, María de los Ángeles, «Galdós y el juego de perspectivas: a propósito de Prim ( 1906)», en Literatura para una nación: estudios sobre el siglo XIX en honor del profesor Enrique Rubio Cremades, ed. José María Ferri Coll et al., Sevilla, Renacimiento, 2019, pp. 459-478.

Ballantyne, Margaret A., «Índice de la Revista de España bajo la dirección de Galdós», Hispania, 1990, 73, 2, PP. 332-344.

Davies, Rhian, «Galdós y la prensa: hacia una revisión crítica de la mina inagotable», en Galdós y el siglo XX. Actas del VIII Congreso Internacional Galdosiano, Las Palmas de Gran Canaria, Casa-Museo Pérez Galdós, 2009. pp. 509-519.

Dendle, Brian J., «Albareda, Galdós and the Revista de España (1868-1873)», en La revolución de I868. Historia, pensamiento y literatura, ed. Clara Lida e Iris Zavala, New York, Las Américas Publishing Company, 1970, pp. 362-377.

García Pinacho, María del Pilar, La prensa como fuente y subtema de los Episodios Nacionales de Benito Pérez Galdós, Madrid, Universidad Complutense, 200I.

Goldman, Peter B. «Galdós and the Politics of Conciliation», Anales Galdosianos, año 4, 1969, pp. 73-83.

González Yanci, María Pilar, «Nuevas revistas sobre Madrid: Madrid Histórico y La llustración de Madrid», Estudios Geográficos, LXX, 267, 2009, Pp. 707-7I4.

Hoar, Leo J., «Politics and Poetry: More Proofs of Galdós's Work for Las Cortes», Modern Language Notes, 88, 2. 1973, pp. 378-397.

Jover Zamora, José María, Realidad y mito de la Primera República, Madrid, Espasa-Calpe, I99I.

|27-| 40. 


\section{JORGE VILCHES GARCÍA}

Menéndez-Onrubia, Carmen, «Un joven periodista llamado Pérez Galdos: testimonios de sus coetáneos», en Actas del X Congreso Internacional Galdosiano, Las Palmas de Gran Canaria, Cabildo de Gran Canaria, 2015, pp. 533-54I.

Ossorio y Bernard, Manuel, Ensayo de un catálogo de periodistas españoles del siglo XIX, Madrid, Imprenta y Litografía de J. Palacios, 1908.

Palomo, María del Mar, «El artículo costumbrista y La Fontana de Oro», en Textos y contextos de Galdós, ed. John W. Kronik y Harriet Turner, Madrid, Castalia, 1994, pp. 39-54.

Pérez Galdós, Benito, Los artículos políticos en la Revista de España, I87/-/872, ed. Brian J. Dendle y Joseph Schraibman, Lexington, Dendle y Schraibman, 1982.

Rubio Jiménez, Jesús, «La llustración de Madrid ( 1870 - I87I). Revista de transición del romanticismo al realismo», Anales de Literatura Española, 26, 2014, pp. 45I-47I.

Sánchez García, Raquel, «Galdós ante el Sexenio revolucionario», Cuadernos de Historia Contemporánea, Extra 2, 2007, pp. 28I-290.

Sapag, Pablo, «La Gaceta de Madrid como instrumento propagandístico de Amadeo de Saboya (I870-1873)», Historia y Comunicación Social, 2006, II, Pp. 199-2I5.

Shoemaker, William H., «Galdós y La Nación», Hispanófila, 25, 1965, pp. 21-50.

Shoemaker, William H., Los artículos de Galdós en «La Nación», I865-/866, I868, Madrid, Ínsula, 1977.

Utt, Roger L., «Galdós' Early Journalism in Madrid and the Las Novedades (Dis-)Connection», Anales galdosianos, Año XIX, 1984, pp. 7I-83.

Vilches, Jorge, Progreso y libertad. El Partido Progresista en la revolución liberal española, Madrid, Alianza Editorial, 2001 .

Vilches, Jorge, «Entre el parlamentarismo y la insurrección: la minoría republicana en las Cortes Constituyentes de la Revolución (I869-|87I)», Historia y Política, 34, 20I5, pp. 239-267.

Vilches, Jorge, «La montaña blanca. La minoría carlista en las Cortes de la Revolución», Memoria y Civilización, 23, 2020, pp. 259-285. 